\title{
Total Skin Electron Beam Therapy with Rotary Dual Technique as Palliative Treatment for Mycosis Fungoides
}

\author{
TOMASZ PIOTROWSKI ${ }^{1,2}$, MAGDALENA FUNDOWICZ ${ }^{3}$ and MARIOLA PAWLACZYK ${ }^{4}$ \\ ${ }^{1}$ Department of Electroradiology, Poznan University of Medical Sciences, Poznan, Poland; \\ ${ }^{2}$ Department of Medical Physics, Greater Poland Cancer Centre, Poznan, Poland; \\ ${ }^{3} 1$ st Radiotherapy Ward, Greater Poland Cancer Centre, Poznan, Poland; \\ ${ }^{4}$ Department of Geriatrics and Gerontology, Poznan University of Medical Sciences, Poznan, Poland
}

\begin{abstract}
Background/Aim: The aim of the study was to retrospectively assess the efficacy and toxicity of total skin electron beam therapy (TSEBT) in patients with primary cutaneous T-cell lymphoma (MF, mycosis fungoides) at various stages of development. Patients and Methods: Treatment results of 40 patients with MF stage IB-III, treated between 2001 and 2015, were reviewed. Median total dose was 32 Gy, delivered to the entire skin surface. Median follow-up was 60 months. Results: Clinical complete response was documented in 29 and partial response in 11 patients. The clinical response significantly influenced overall survival $(O S)(p=0.002)$ and progression-free survival (PFS) $(p<0.001)$. Mean OS was 76 months. Mean PFS was 48.9 months and current one-and two-year PFS were $67.5 \%$ and $55 \%$, respectively. A statistically significant correlation was found between partial and total remission time and stages of the lymphoma $(p=0.015)$. Conclusion: TSEBT is an efficient and well-tolerated palliative treatment for symptomatic primary cutaneous T-cell lymphoma.
\end{abstract}

Mycosis fungoides (MF) constitutes the most common primary cutaneous T-cell lymphoma. The disease process starts as pruritic, erythematous patches, followed by plaques at the infiltrating stage, and tumors and ulcers in the last stage. As the disease progresses, pruritus and erythema intensify and thicken at the infiltrating stage, when healthy skin becomes infiltrated. Pruritus lessens or subsides

This article is freely accessible online.

Correspondence to: Adj. Prof. Tomasz Piotrowski, Department of Medical Physics, Greater Poland Cancer Centre, Garbary 15 st, 61-866 Poznan, Poland. Tel: +48 618850763, e-mail: tomasz.piotrowski@wco.pl

Key Words: Mycosis fungoides, radiotherapy, progression free survival, overall survival, toxicity. altogether when ulcers appear or during progression of the neoplastic process to the tumor stage. Lymph node and internal organ (liver, lungs, spleen) metastases may also occur during the course of the disease. MF progresses over many years and the prognosis depends on the stage of the disease (1). The classification of mycosis fungoides has been presented in various studies published by the International Society for Cutaneous Lymphomas $(2,3)$.

The diagnosis is based on histopathological and immunohistochemical examination of the biopsied skin samples. Early-stage skin lesions present a particular challenge as they may imitate inflammatory dermatoses such as psoriasis, eczema, atopic dermatitis, or erythroderma of unknown etiology. In more advanced stages of the disease, trephine biopsy, as well as an ultrasound examination of the lymph nodes and the abdominal cavity to assess the liver and the spleen are recommended to evaluate disease progression. Clinical and histological changes imitating MF and other cutaneous lymphomas may result from the intake of certain medications which cause cutaneous pseudolymphomas - a significant diagnostic challenge for histopathology and differential diagnosis (4).

The treatment in the early stages of the disease aims at alleviating the symptoms while causing the least possible toxicity. Topical high-potency glucocorticosteroids, psoralen plus ultraviolet A radiation (PUVA-therapy) or ultraviolet B (UVB), topical bexarotene, topical radiation therapy or, in case of generalized lesions, Total Skin Electron Beam Therapy (TSEBT) is recommended. In more advanced stages, PUVA-therapy, interferon-alfa, chemotherapy, bexarotene therapy and TSEBT are used. As for chemotherapy, none of the treatment regimens has an advantage over the others and the overall health condition of the patient, the risk for myelosuppression and complications should be taken into consideration when deciding the optimal therapy; in case of slow progression of the disease, monotherapy with low doses of methotrexate, cyclophosphamide, and etoposide is advised. 


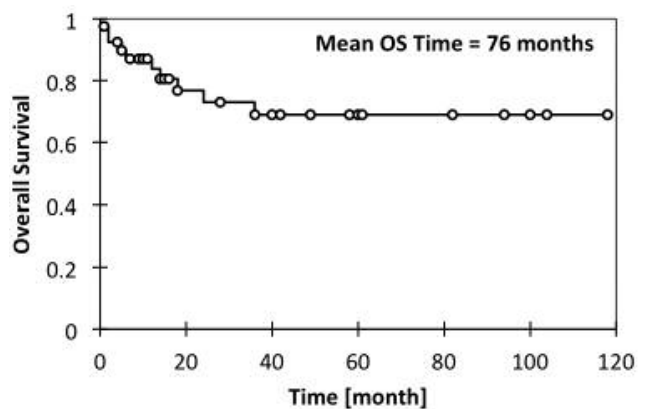

Figure 1. Overall survival for the patients treated with the rotary dual total skin electron beam technique.

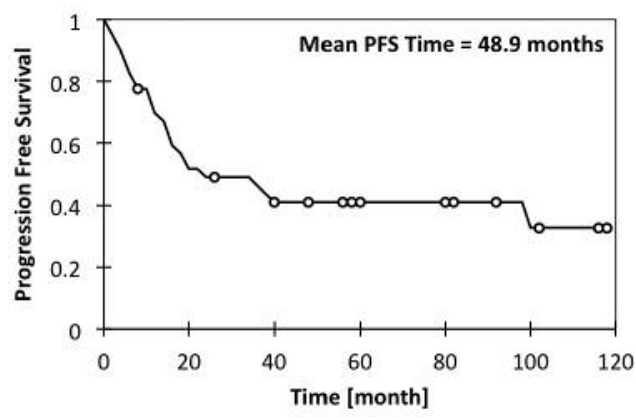

Figure 2. Progression-free survival for the patients treated with the rotary dual total skin electron beam technique.

Table I. Overall survival (OS) and progression-free survival (PFS) versus remission after therapy, age, disease stage, sex, radiation dose during radiation therapy $(R T)$ and time elapsed between diagnosis and $R T$ commencement. The p-value of alfa=0.05 was considered as statistically significant.

\begin{tabular}{|c|c|c|c|c|c|}
\hline \multirow[t]{2}{*}{ Group } & \multirow{2}{*}{$\begin{array}{c}\text { Number }(\%) \\
\text { of patients }\end{array}$} & \multicolumn{2}{|c|}{ OS } & \multicolumn{2}{|c|}{ PFS } \\
\hline & & $\begin{array}{l}\text { Mean survival time } \\
\text { (months) }\end{array}$ & $\begin{array}{c}\text { log-rank } \\
p \text {-Value }\end{array}$ & $\begin{array}{c}\text { Mean survival time } \\
\text { (months) }\end{array}$ & $\begin{array}{c}\text { log-rank } \\
p \text {-Value }\end{array}$ \\
\hline \multicolumn{6}{|l|}{ Remission } \\
\hline Complete & $29(72.5)$ & 84.0 & \multirow[t]{2}{*}{0.002} & 65.6 & \multirow[t]{2}{*}{$<0.001$} \\
\hline Partial & $11(27.5)$ & 7.2 & & 5.6 & \\
\hline \multicolumn{6}{|l|}{ Age* (years) } \\
\hline$<60$ & $19(47.5)$ & 52.0 & \multirow[t]{2}{*}{0.206} & 36.1 & \multirow[t]{2}{*}{0.433} \\
\hline$>60$ & $21(52.5)$ & 66.4 & & 45.0 & \\
\hline \multicolumn{6}{|l|}{ Stage } \\
\hline IB & $14(35)$ & 65.2 & \multirow[t]{4}{*}{0.542} & 58.2 & \multirow[t]{4}{*}{0.489} \\
\hline IIA & $6(15)$ & 32.0 & & 28.3 & \\
\hline IIB & $14(35)$ & 37.2 & & 26.3 & \\
\hline III & $6(15)$ & 8.7 & & 7.8 & \\
\hline \multicolumn{6}{|l|}{ Gender } \\
\hline Male & $32(80)$ & 76.6 & \multirow[t]{2}{*}{0.662} & 46.3 & \multirow[t]{2}{*}{0.439} \\
\hline Female & $8(20)$ & 37.6 & & 34.1 & \\
\hline \multicolumn{6}{|c|}{ Delivered Dose (Gy) } \\
\hline From 34 to 40 & $19(47.5)$ & 62.7 & \multirow[t]{3}{*}{0.615} & 38.7 & \multirow[t]{3}{*}{0.467} \\
\hline From 20 to 34 & $17(42.5)$ & 86.0 & & 60.6 & \\
\hline Up to 20 & $4(10)$ & 25.1 & & 5.4 & \\
\hline \multicolumn{6}{|c|}{ Time of MF diagnosis before RT (years) } \\
\hline$<1$ & $29(72.5)$ & 77.6 & \multirow[t]{2}{*}{0.733} & 53.8 & \multirow[t]{2}{*}{0.329} \\
\hline$>1$ & $11(27.5)$ & 43.4 & & 35.4 & \\
\hline
\end{tabular}

OS: Overall survival; PFS: progression-free survival; RT: radiation therapy; MF: mycosis fungoides. *Median age 60 years.

To the best of our knowledge, no treatment standards have been established so far (5).

The aim of the study was to present the effects of TSEBT in 40 patients with mycosis fungoides.

\section{Patients and Methods}

A total of 40 patients (32 men and 8 women) with primary cutaneous T-cell MF (stages IB-III), were treated using TSEBT between 2001 and 2015. Mean patient age was 60 years (range $=40-84$ years). Fourteen patients were stage IB, 6 - stage IIA, 14 - stage IIB and 6 - stage III. Time elapsed between the diagnosis and radiation therapy commencement was $<1$ year (mean: 6 months) in 29 patients and $>1$ year (from 14 to 72 months; mean: 47.1 months) in the remaining 11 patients. The diagnosis was confirmed using histopathological and immunohistochemical tests of the biopsied samples. All patients had received PUVA, interferon alpha or chemotherapy before radiation therapy. All subjects complained of pruritus, pain, and non-healing ulcers on the skin before therapy commencement. 


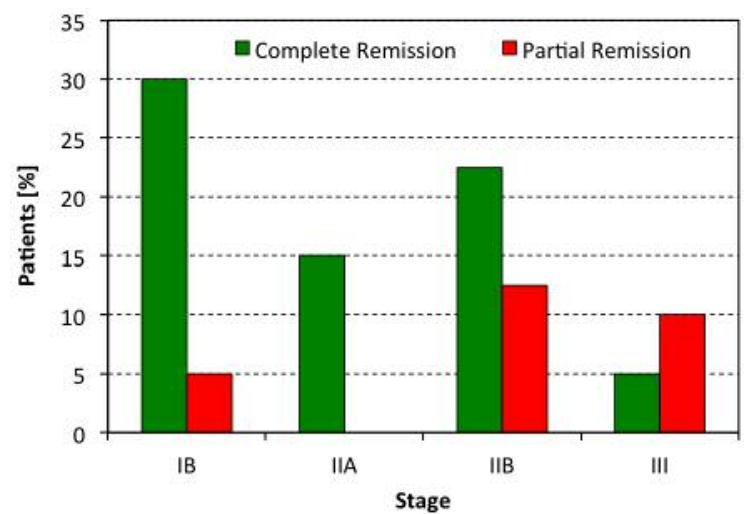

Figure 3. Stratification of patients in terms of remission and disease stage.

The patients received radiation in the vertical position on a rotating platform using rotary dual technique, delivering an electron beam at $6 \mathrm{MeV}$. Median total dose was 32Gy (range=12-40 Gy), with $1.5 \mathrm{~Gy} /$ day four times/week, delivered to the entire skin. Additionally, a boost dose of 10-16 Gy was delivered to the areas, which did not receive the full dose during TSEB (soles, palms, vertex, perineum, inner areas of the shoulders, forearms, and thighs). Time elapsed between radiation therapy commencement and the diagnosis was approximately 17 months (range $=1-72$ months) $(6,7)$.

Data were analyzed for the overall survival (OS) and skinprogression-free survival (PFS). Statistical analyses were carried out using log-rank test (Cox) and Kaplan-Meier's estimation. Significance was defined as the $p$-value of $<0.05$. Documented long-term side-effects were classified according to the RTOG/EORTC Late Radiation Morbidity Scoring Scheme (CTCAE version 3.0).

\section{Results}

Mean observation time was 60 months (range $=1-120$ months). Complete and partial remissions were achieved in $29(72.5 \%)$ and $11(27.5 \%)$ patients, respectively. Alleviation of pruritus and diminished and/or whitening lesions were achieved in all subjects. Mean time to progression was 16 months (range $=1-40$ months). The overall survival (OS) and progression free survival (PFS) are presented in Figures 1 and 2, respectively. Mean OS and PFS were 76 and 48.9 months, respectively. One- and two-year PFSs were $67.5 \%$ and 55\%, respectively (Figure 2). Both, OS and PFS depended on the degree of the remission after radiation therapy ( $p$-values of 0.002 and $<0.001$, respectively).

Table I presents the relationship between OS and PFS and degree of the remission after a course of radiation therapy, age, disease advancement, sex, radiation therapy (RT) dose, time elapsed between the diagnosis and RT commencement. Statistically significant differences were observed only for

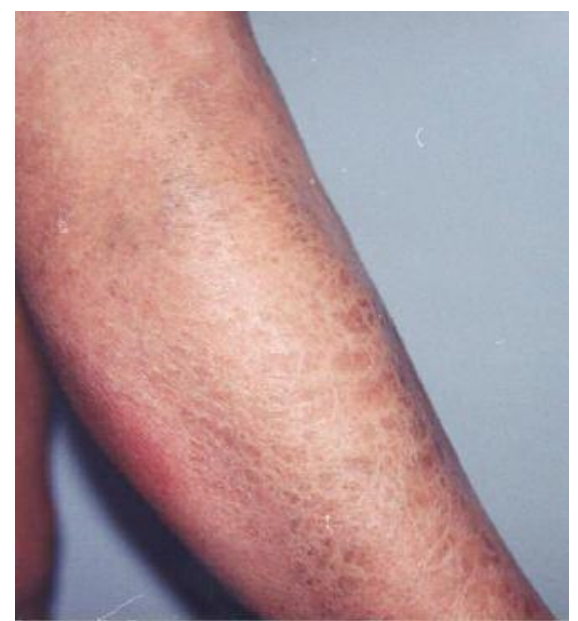

Figure 4. Dry skin after the course of TSEBT.

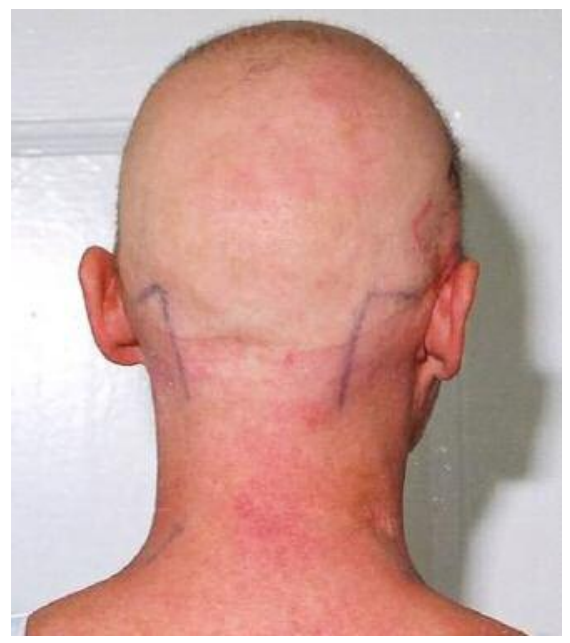

Figure 5. Alopecia after the course of TSEBT.

the degree of the remission, both for OS $(p=0.002)$ and PFS $(p<0.001)$. In that group, mean survival times for complete remission (CR) and partial remission (PR) were 84 and 65.6 months and 7.2 and 5.6 months for OS and for PFS, respectively. No statistically significant differences were detected for the remaining parameters. Nevertheless, a declining tendency for the relationship between mean survival and disease stage was noted (Table I). Shorter mean survival times were observed among female patients (37.6 and 34.1 months for OS and PFS, respectively) as compared to male patients (76.6 and 46.3 months for OS and PFS, respectively). Longer mean survival times were found for patients from the $<1$ year between diagnosis and therapy commencement group (Table I). The differences were not statistically significant. 
Table II. Stratification of patients in terms of remission and disease stage.

\begin{tabular}{lccccc}
\hline Remission & \multicolumn{4}{c}{ Stage } & \multicolumn{2}{c}{$\begin{array}{c}\text { Mann-Whitney } \\
p \text {-Value }\end{array}$} \\
\cline { 2 - 5 } & IB & IIA & IIB & III & \\
\hline Complete & $12(30 \%)$ & $6(15 \%)$ & $9(22.5 \%)$ & $2(5 \%)$ & 0.015 \\
Partial & $2(5 \%)$ & $0(0 \%)$ & $5(12.5 \%)$ & $4(10 \%)$ & \\
\hline
\end{tabular}

Number of patients (percentage).
Table III. Number of patients without recurrence versus disease stage.

\begin{tabular}{lcc}
\hline Stage & $\begin{array}{c}\text { Number }(\%) \\
\text { of patients }\end{array}$ & $\begin{array}{c}\text { mPFS } \\
\text { (months) }\end{array}$ \\
\hline IB & $6(15 \%)$ & 78 \\
IIA & $3(7.5 \%)$ & 110 \\
IIB & $8(20 \%)$ & 33 \\
III & $2(5 \%)$ & 80 \\
\hline
\end{tabular}

mPFS: Mean time of progression-free survival.

Table IV. Progression-free survival and overall survival for patients treated by high total dose total skin electron beam therapy. Overview of the literature.

\begin{tabular}{|c|c|c|c|c|}
\hline Author & Stage (\% of patients) & ATD (Gy) & mPFS (months) & mOS (months) \\
\hline Lindahl et al. (18) & $\begin{array}{c}\text { IA }(5.7 \%) \\
\text { IIA }(40 \%) \\
\text { IIB }(48.6 \%) \\
\text { IIIA }(5.7 \%)\end{array}$ & 30 & 9 & N.A. \\
\hline Navi et al. (21) & $\begin{array}{l}\text { IIA (57\%) } \\
\text { IIB (43\%) }\end{array}$ & 36 & $\begin{array}{l}102 \text { (IIA) } \\
35 \text { (IIB) }\end{array}$ & $\begin{array}{c}131 \text { (IIA) } \\
56 \text { (IIB) }\end{array}$ \\
\hline Kamstrup et al. $(12,13)$ & $\begin{array}{l}\text { IIA }(60 \%) \\
\text { IIB }(20 \%) \\
\text { IIIA }(20 \%)\end{array}$ & 10 & 5.2 & N.A. \\
\hline Hauswald et al. (24) & $\begin{array}{c}\text { IIB }(18 \%) \\
\text { III }(5 \%) \\
\text { IVA }(45 \%) \\
\text { IVB }(32 \%)\end{array}$ & 29 & 5 & 10 \\
\hline Current study* & $\begin{array}{l}\text { IB }(35 \%) \\
\text { IIA }(15 \%) \\
\text { IIB }(35 \%) \\
\text { III }(15 \%)\end{array}$ & 32 & 48.9 & 76 \\
\hline
\end{tabular}

ATD: Average total dose; mPFS: mean time of progression-free survival; mOS: mean time of overall survival. *Our study included high-dose and low-dose schemes.

Despite the lack of a relationship between disease stage and OS and PFS, a statistically significant association was observed between the degree of remission and disease stage $(p=0.015)$ (Table II and Figure 3). No statistically significant relationships were found for the remaining parameters (age, sex, radiation dose during therapy, and time elapsed between diagnosis and therapy commencement).

Recurrence was found in 21 (52.5\%) patients. Complete remission after a course of radiation therapy was achieved in $19(47.5 \%)$ patients without recurrence. That group is characterized by notably increased rates of patients without recurrence versus disease stage (Table III). A relatively high rate of patients without recurrence among subjects with the disease stage of IIB results from a short mean time without disease progression.

Out of the study group, 10 patients died (4 due to disease progression and 6 due to causes unrelated with lymphoma).
No statistically significant relationships were found between disease progression and degree of remission after radiation therapy ( 2 patients $-\mathrm{CR}, 2$ patients - PR), or disease stage (2 patients - IB, 2 patients - IIA and III). Skin reaction due to radiation was observed in all subjects during or after therapy: dry skin covering $<10 \%$ body surface area associated with erythema or pruritus (Figure 4) at 3-4 weeks and hair loss (Figure 5) and asymptomatic separation of the nail bed form the nail plate or nail loss at 5-6 weeks of therapy.

\section{Discussion}

Primary skin lymphomas remain relatively rare. Thus, the number of randomized studies, which might lead to standardized methods of treatment is limited at best. The therapy is multi-disciplinary and the team should include 
dermatologists, clinical oncologists, hematologists and radiation therapists. The management depends on the disease stage, the overall condition of the patient and therapeutic facilities of the centers. Despite the introductions of new drugs and treatment regimes, effective therapy strategies remain to be elucidated. The choice of therapy, especially in patients with low malignant potential disease, must be influenced by the fact that the disease, at least for a considerable duration of time, is restricted to the skin. Therefore, the therapy should monitor the condition of the skin, alleviate subjective symptoms and prevent disease progression. TSEBT is an example of treatment, that may be applied in such cases (8). The dose is delivered using one of various radiation techniques, with six dual field, rotational, and rotary dual techniques among the most common examples (9).

The results of treatment of 40 patients undergoing treatment with rotary dual technique have been presented in our study. The degree of remission after radiation therapy proved to be the main determining factor for the overall survival and progression-free survival ( $p$-value of 0.002 and $<0.001$, respectively) (Table I). Disease stage directly affects the degree of the remission ( $p=0.015)$ (Table II and Figure 3). Our findings are consistent with earlier reports of Suzuki et al. (10) and Kamarashev et al. (11). The results presented in our study were obtained for patients treated with high (from $34 \mathrm{~Gy}$ to $40 \mathrm{~Gy}$ ), medium (from $20 \mathrm{~Gy}$ to $34 \mathrm{~Gy}$ ) and low (up to $20 \mathrm{~Gy}$ ) doses (Table I). Several studies presented low-dose schemes of TSEBT. Kamstrup et al. $(12,13)$ investigated the possibility of using low-dose schemes which lower TSBT toxicity. Their study included patients with stages I and II of the disease. Low doses were well-tolerated by all subjects. The most common adverse symptoms included temporary hair loss (56\%) and eye irritation $(33 \%)$. The use of low total doses allows for repeat TSEBT but regression time for such scheme is very short (26 months). Thus, low-dose TSEBT induces clinical response but not long-term disease control, which is consistent with our findings. Mean remission time for the 4 patients treated with total dose $<20$ Gy was 5.4 months (Table I). We believe that it is necessary to analyze the therapeutic effects of low-dose schemes combined with other treatment methods to prolong remission time.

For now, high-dose schemes remain the therapeutic standard. A statistically significantly higher rate of complete remissions was achieved in patients treated with high doses as compared to studies, which used low-dose schemes (14$16)$, which is also consistent with our observations. Mean PFS was 60.6 months and 38.7 months for patients treated with 20-34 Gy and 34-40 Gy, respectively (Table I). Shorter PFS for the dose of 34-40 Gy resulted from higher rates of patients with stage III disease. Table IV presents the results of several studies using low- and high-dose schemes (disease stage, therapeutic dose, OS and PFS).
Earlier reports, for example Kamstrup et al. (12) and Harrison et al. (17), had suggested a dose-response correlation in TSEBT. Lower doses (<30 Gy) were always associated with lower response to treatment $(12,18-20)$. In a study by Lindhal et al. (18), 25 out of 35 patients received the high dose of $30 \mathrm{~Gy}$, and 10 received the dose of $4 \mathrm{~Gy}$. The lower dose was proven to be insufficient and response to treatment was found in only $10 \%$ of the patients. Time to disease progression among the patients who received the higher dose was 9 months. Similar findings were confirmed by our study although the relationship lacked statistical significance. Navi et al. (21) treated a group of 180 patients with MF (stages T3 and T4), who received a 36 Gy dose of TSEBT (30-40 Gy) as primary therapy. As in the case of our patients, the side effects of the therapy included skin dryness, erythema, hair loss, as nail shedding.

Application of TSEBT as secondary therapy increases the possibility of remission even in patients with stage III MF, which was demonstrated by our study. We treated 6 patients with stage III disease and achieved complete remission in 2 cases. Partial remission was achieved in 4 subjects. Response to treatment was assessed on the basis of the clinical and histopathological evaluation of skin samples. The latest studies evaluated the applicability of positron emission tomography to evaluate the response to treatment in MF, but the results remain inconclusive (22). The search for radiosensitizers, that might increase the effectiveness of radiation therapy, continues (23).

\section{Conclusion}

As far as MF patients are concerned, TSEBT remains a welltolerated method, allowing for alleviation of subjective symptoms (pruritus), remission of skin lesions and extension of time to disease progression. TSEBT is used in cases when phototherapy, photochemotherapy, and interferon-alpha fail to produce disease remission.

\section{References}

1 Trautinger F, Knobler R, Willemze R, Peris K, Stadler R, Laroche L, D'Incan M, Ranki A, Pimpinelli N, Ortiz-Romero P, Dummer R, Estrach $\mathrm{T}$ and Whittaker S: EORTC consensus recommendations for the treatment of mycosis fungoides/Sezary syndrome. Eur J Cancer 42: 1014-1030, 2006.

2 Olsen E, Vonderheid E, Pimpinelli N, Willemze R, Kim Y, Knobler R, Zackheim H, Duvic M, Estrach T, Lamberg S, Wood G, Dummer R, Ranki A, Burg G, Heald P, Pittelkow M, Bernengo MG, Sterry W, Laroche L, Trautinger F and Whittaker $\mathrm{S}$ : Revisions to the staging and classification of mycosis fungoides and Sezary syndrome: a proposal of the International Society for Cutaneous Lymphomas (ISCL) and the cutaneous lymphoma task force of the European Organization of Research and Treatment of Cancer (EORTC). Blood 110: 1713-1722, 2007. 
3 Olsen E, Whittaker S, Kim Y, Duvic M, Prince HM, Lessin SR, Wood GS, Willemze R, Demierre MF, Pimpinelli N, Bernengo MG, Ortiz-Romero PL, Bagot M, Estrach T, Guitart J, Knobler R, Sanches JA, Iwatsuki K, Sugaya M, Dummer R, Pittelkow M, Hoppe R, Parker S, Geskin L, Pinter-Brown L, Girardi M, Burg G, Ranki A, Vermeer M, Horwitz S, Heald P, Rosen S, Cerroni L, Dreno B and Vonderheid EC: Clinical end points and response criteria in mycosis fungoides and Sezary syndrome: a consensus statement of the International Society for Cutaneous Lymphomas, the United States Cutaneous Lymphoma Consortium, and the Cutaneous Lymphoma Task Force of the European Organization for Research and Treatment of Cancer. J Clin Oncol 29: 2598-2607, 2011.

4 Olek-Hrab K and Silny W: Diagnostics in mycosis fungoides and Sezary syndrome. Rep Pract Oncol Radiother 19: 72-76, 2014.

5 Mazzeo E, Rubino L, Buglione M, Antognoni P, Magrini SM, Bertoni F, Parmiggiani M, Barbieri P and Bertoni F: The current management of mycosis fungoides and Sezary syndrome and the role of radiotherapy: principles and indications. Rep Pract Oncol Radiother 19: 77-91, 2014.

6 Piotrowski $\mathrm{T}$ and Malicki $\mathrm{J}$ : The rotary dual technique for total skin irradiation in the treatment of mycosis fungoides - a description of applied method. Rep Pract Oncol Radiother 11: 19, 2006.

7 Piotrowski T, Fundowicz D, Pawlaczyk M and Malicki J: Thermoluminescent dosimetry in rotary dual technique of the total skin electron irradiation. Neoplasma 50: 41-46, 2003.

8 Funk A, Hensley F, Krempien R, Neuhof D, Van Kampen M, Treiber M, Roeder F, Timke C, Herfarth K, Helmbold P, Debus $\mathrm{J}$ and Bischof $\mathrm{M}$ : Palliative total skin electron beam therapy (TSEBT) for advanced cutaneous T-cell lymphoma. Eur J Dermatol 18: 308-312, 2008.

9 Piotrowski T, Milecki P, Skorska M and Fundowicz D: Total skin electron irradiation techniques: a review. Postep Derm Alergol 30: 50-55, 2013.

10 Suzuki S, Ito K, Ito M and Kawai K: Prognosis of 100 patients with mycosis fungoides and Sezary syndrome. J Dermatol Sci 57: 37-43, 2010.

11 Kamarashev J, Theler B, Dummer R and Burg G: Mycosis fungoides-analysis of the duration of disease stages in patients who progress and the time point of high-grade transformation. Int J Dermatol 46: 930-935, 2007.

12 Kamstrup M, Lindahl L, Gniadecki R, Iversen L, Skov L, Petersen PM, Loft A and Specht L: Low-dose total skin electron beam therapy as a debulking agent for cutaneous T-cell lymphoma: an open-label prospective phase II study. $\mathrm{Br} \mathrm{J}$ Dermatol 166: 399-404, 2012.

13 Kamstrup M, Spechta L, Skovgaard G and Gniadecki R: A prospective, open-label study of low-does total skin electron beam therapy in Mycosis Fungoides. Int J Radiation Oncology Biol Phys 71: 1204-1207, 2008

14 Zhao S and Song S: Comparison of low-dose and standard-dose total skin electron beam therapy for mycosis fungoides. Int $\mathrm{J}$ Radiat Oncol Biol Phys 99: E435-E436, 2017.
15 Morris SL, Scarisbrick J, Frew JJ, Irwin C, Grieve R, Humber C, Kuciejewska A, Bayne S, Weatherhead S, Child F, Wain M and Whittaker S: The results of low dose total skin electron beam radiotherapy (TSEB), in patients with mycosis fungoides from the UK cutaneous lymphoma group. Int J Radiat Oncol Biol Phys 99: 627-633, 2017.

16 Hoppe RT, Harrison C, Tavallaee M, Bashey S, Sundram U, Li S, Million L, Dabaja B, Gangar P, Duvic M and Kim YH: Lowdose total skin electron beam therapy as an effective modality to reduce disease burden in patients with mycosis fungoides: Results of a pooled analysis from 3 phase-II clinical trials. J Am Acad Dermatol 72: 286-292, 2015.

17 Harrison C, Young J, Navi D, Riaz N, Lingala B, Kim J and Hoppe RT: Revisiting low-dose total skin electron beam therapy in mycosis fungoides. Int J Radiat Oncol Biol Phys 81: 651-657, 2011.

18 Lindahl LM, Kamstrup MR, Petersen PM, Wiren J, Fenger-Gron M, Gniadecki R, Iversen L and Specht L: Total skin electron beam therapy for cutaneous T-cell lymphoma: a nationwide cohort study from Denmark. Acta Oncol 50: 1199-1205, 2011.

19 Neelis KJ, Schimmel EC, Vermeer MH, Senff NJ, Willemze R and Noordijk EM: Low-dose palliative radiotherapy for cutaneous B- and T-cell lymphomas. Int J Radiat Oncol Biol Phys 74: 154-158, 2009.

20 Hoppe RT: Total skin electron beam therapy in the management of mycosis fungoides. Front Radiat Ther Oncol 25: 80-89, 1991.

21 Navi D, Riaz N, Levin Y, Sullivan N, Kim Y and Hoppe RT: The Stanford University experience with conventional-does, total skin electron beam therapy in the treatment of generalized patch or plaque (T2) and tumor (T3) mycosis fungoides. Arch Dermatol 147: 561-567, 2011.

22 Kuo PH, Carlson KR, Christensen I, Girardi M and Heald PW: FDG-PET/CT for the evaluation of response to therapy of cutaneous T-cell lymphoma to vorinostat (suberoylanilide hydroxamic acid, SAHA) in a phase II trial. Mol Imaging Biol 10: 306-314, 2008.

23 Roberge D, Muanza T, Blake G, Shustik C, Vuong T and Freeman CR: Does adjuvant alpha-interferon improve outcome when combined with total skin irradiation for mycosis fungoides? Br J Dermatol 156: 57-61, 2007.

24 Hauswald H, Zwicker F, Rochet N, Uhl M, Hensley F, Debus J, Herfarth $\mathrm{K}$ and Bischof M: Total skin electron beam therapy as palliative treatment for cutaneous manifestations of advanced, therapy-refractory cutaneous lymphoma and leukemia. Radiat Oncol 7: 118-124, 2012. 